\title{
PINELITIAN KUALITAS GAS BUANG PADA INDUSTRI BAN
}

Oleh : Kusumo Retno Winahyu, Irene Sri Sukaeni, Justinus Edy Dahono

\section{AIISTRACT}

The weicarch of air pollution quality of rubber tyre industry to check rubber tyre air polluIitin gialiry. Taking samples should be done on several tyre rubber industries in the middle it liwa. Each of industries observed by two samplinglocation, it was taken from rubber tyre ime essing area and $\mathrm{NO}_{3}, \mathrm{NH}_{3} \mathrm{H}_{2} \mathrm{~S}$ and particles for several sampling location on rubber Gite pmecssing area. Many results of the research shown sampling data of Oxidants at process. ing area are $0,2580-1,4670 \mathrm{ppm}$ higher than $0,10 \mathrm{ppm}$ standard concerned, while data of isidants at ambient quality have range 0,4144-1,6235 ppm higher than 0,10 ppm environmental standar quality for amoient. It"s given range between $11,7034-18,1179 \mathrm{ppm} \mathrm{NH}$ higher than 2,00 ppm standar quality for processing area and the results of particles analizing area $0.2727-1,6880 \mathrm{mgr} / \mathrm{m} 3$ higher than $0,26 \mathrm{mgr} / \mathrm{m} 3$ standar quality for ambient. Many fesulis of parameters still agree with standard concermed. $\mathrm{H}_{2} \mathrm{~S}$ for ambient have given range berween 0,0051-0,0216 ppmlower than 0,03 ppm standard for ambient and $\mathrm{H}_{2} \mathrm{~S}$ for rubber iye processing area between 0,0029-0,0520 ppm lower than 10,00 ppm standard for processing area. The results of particles analizing for processing area have given range $1,1440-1,2632 \mathrm{mgr} / \mathrm{m}^{3}$ lower $10,00 \mathrm{mgr} / \mathrm{m}^{3}$.

\section{INTISARI}

Prnelitian kualitas gas buang pada industri Ban bertujuan untuk memperoleh data kualitas industri gas buang industri Ban. Pengambilan contoh uji udara dilakukan pada beberapa industri Ban di wilayah Wowa Tengah, masing-masing diamati pada dua lokasi pengambilan sampel udara, yaitu pada ruang proses produksi serta udara ambien atau udara lingkungan disekitar pabrik. Parameter yang diteliti meliputi oksidan, Sulfur Oksida, Hidrogen Sulfida, Nitrogen Oksida, Amoniak serta Debu, Hasil penelitian menunjukkan bahwa tidak terdeteksi adanya Sulfur Oksida, Nitrogen Oksida, serta Amoniak pada lokasi sampling udara lingkungan (ambien) udara ruang proses bagi parameter $\mathrm{SO}_{\mathbf{r}} \& \mathrm{NO}_{\text {, }}$ pada lokasi sampling ruang proses produksi bagi parameter $\mathrm{NH}_{3}$ telah melampaui batas yang dipersyaratkan yaitu mempunvai kisaran sebesar 11,7034-18,1179 ppm > 2,00 ppm. Parameter Oksidan terdeteks. sudah diatas baku mutu pada lokasi pengambilan sampel pada ruang ambien dan ruang proses. Yaitu sebesar 0,4144-1,6235 ppm >0,10 ppm untuk ruang ambien sedangkan hasil penelitian pada ruang proses yaitu sebesar 0,2580 - 1,4670 ppm $>0,10 \mathrm{ppm}$. Parameter Debu pada ruang ambien sudah diatas baku mutu yaitu terdeteksi sebesar 0,2390 - 1,6880 $\mathrm{mgr} / \mathrm{m} 3>0,26 \mathrm{mgr} / \mathrm{m}^{3}$, sedangkan konsentrasi debu pada lokasi pengamatan ruang proses masih di bawah baku mutu yaitu sebesar $1,1440-1,2632 \mathrm{mgr} / \mathrm{m}^{3}<10,00 \mathrm{mgr} / \mathrm{m}^{3}$.

\section{PENDAHULUAN}

Di Indonesia komoditi Barang Karet masih berperan sebagai salah satu

Vol. XII No. 24 Th. $1996 / 1997$ 
primadona ekspor. Berdasarkan data Biro Pusat Statistik, diperoleh informasi bahwa, ekspor "Ban Dalam" pada tahun 1993 mencapai 7.329.171 U\$, sedangkan "Ban Luar" mencapai 75.181.757 U\$.

Adanya peningkatan industri Ban Karet sangat menggembirakan karena diharapkan meningkatkan devisa negara. Namun disisi lain peningkatan ini akan menimbulkan dampak negatif, yaitu peningkatan polusi gas buang serta partikel debu yang berasal dari kegiatan proses.

Melihat fenomena tersebut untuk menanggulangi hal tersebut pemerintah telah mengantisipasi dengan peraturan-peraturan yang ketat perlu dilakukan penanganan yang tepat, antara lain telah dikeluarkan juga perundang-undangan masalah pencemaran lingkungan tentang baku mutu udara yang tertuang dalam SK Menteri Lingkungan Hidup, yaitu : Keputusan Menteri No. 03/MENKLH/II/91, tentang Baku Mutu Udara Ambien serta Baku Mutu Udara Pada Ruang Proses Produksi.

\section{Tujuan Penelitian :}

Untuk monitoring kualitas gas buang pada industri Ban.

\section{Sasaran Penelitian :}

Industri Ban yang ada di Jawa Tengah.

\section{Tinjauan Pustaka :}

Pesatnya perkembangan industri barang dari karet antara lain industri Ban di Indonesia amat menggembirakan, namun disisi lain industri ini dapat menimbulkan dampak negatif bagi lingkungan, yaitu timbulnya gas buang serta partikel debu ke udara yang dapat berperan sebagai bahan pencemar di sekitar lingkungan pabrik maupun lingkungan kerja.

Pada prinsipnya partikel debu dapat didefinisikan sebagai hadirnya kontaminan di ruang terbuka dengan konsentrasi dan durasi sedemikian rupa sehingga mengakibatkan gangguan bagi makluk hidup dan tumbuh-tumbuhan serta dapat mempengaruhi keindahan estetika. Sedangkan gas pencemar atau gas buang pada umumnya berupa karbon monoksida/dioksida, gas amoniak, asam sulfida, nitrogen oksida/dioksida, maupun hidrokarbon.

Pada kenyataanya pencemaran udara tidak hanya diakibatkan oleh adanya kegiatan industri saja, namun juga oleh adanya kegiatan transportasi, penambang an serta adanya bencana alam berupa letusan gunung berapi, serta angin topan yang mampu menerbangkan debu sepanjang puluhan kilometer.

Fenomena pencemaran udara yang dikenal saat ini yaitu kabut London, Smog
Phesekima Los Angeles, Hujan Asam di Amerika Utara serta isu aktual yang Hementabal anat ini berupa efek rumah kaca dan penipisan lapisan ozon. Kabut Lumban teramati setelah revolusi industri abad ke 18 yaitu setelah diperkenalkan jumemunan bahan bakar fosil (batu bara) sebagai penggerak mesin uap yang sangat a teienaif Smos Photokimia Los Angeles, semula diperkirakan sama dengan Kabut

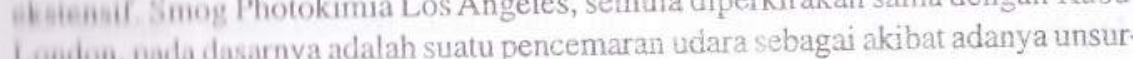
tuaie pencemar udara yang terkandung dalam gas buang kendaraan bermotor.

Ilujan Asam disebabkan oleh gas buang proses pembakaran bahan bakar anil it daerah perkotaan, baik yang bersumber dari PLTU maupun kendaraan vamaiar Akumulasi gas rumah kaca, juga disebabkan oleh pembakaran bahan bay fouil namun dalam skala y ang lebih besar. Sedangkan penipisan lapisan ozon, menipakan fenomena yang juga dengan skala waktu yang lebih panjang.

Penyebab utamanya yaitu unsur-unsur yang mempunyai kestabilan sangat inses yaitu : unsur bahan pendingin yang dikenal dengan Chlorofluoro-carbon (C)"s)

Dalam kaitannya dengan masalah kesehatan terhadap makluk hidup, gasah tersebut merupakan polutan yang berpengaruh buruk dalam kadar diatas baku muii yang telah ditetapkan, atau dalam kadar rendah dengan waktu kontak yang angat panjang. Karbon monoksida pada konsentrasi tinggi dapat menyebabian tematian. Pengaruh beracun $\mathrm{CO}$ terhadap tubuh manusia disebabkan oleh reaksi untara $\mathrm{CO}$ dengan Haemoglobin $(\mathrm{Hb})$ di daiam darah. Haemoglobin di dalam darah ieara normal berfungsi dalam sistem transpor untuk membawa oksigen dalam linauk oksi haemoglobin atau $\mathrm{CO}_{2} \mathrm{Hb}$ dari paru-paru ke dalam sel-sel tubuh serta membawa $\mathrm{CO}_{2}$ dalam bentuk $\mathrm{CO}_{2} \mathrm{Hb}$ dari sel-sel tubuh ke dalam paru-paru. Thriadinya reaksi karboksihaemoglobin dapat menyebabkan kernampuan darah untuk transpor oksigen menjadi berkurang. Afinitas CO terhadap haemoglobin 200 kali lebih besar dari pada afinitas oksigen terhadap haemoglobin, Hal ini akan mengakibatkan penderita merasa mual, pusing dan pada akhirnya menjadi pingsan.

Polutan $\mathrm{SO}_{x}$ akan menyebabkan iritasi terhadap sistem pernafasan. Beberapa penelitian menunjukkan bahwa iritasi tenggorokan terjadi pada konsentrasi $\mathrm{SO}_{3}$ sebesar 5 ppm atau lebih. Sedangkan partikel debu untuk ukuran tertentu dapat mengendap pada paru-paru. Keadaan ini dapat lebih membahayakan apabila partikel debu mempunyai sifat beracun. Partikel debu masuk ke dalam tubuh manusia melalui sistem pernafasan. Faktor yang paling berpengaruh terhadap sistem pernafasan adalah ukuran partikel, karena ukuran partikel yang menentukan seberapa jauh penetrasi partikel ke dalam sistem pernafasan, makin kecil ukuran partike yangterhisap maka semakin dalam partikel masuk jauh ke dalam sistem pernafasan, makin kecil ukuran partikel yang terhisap maka semakin dalam partikel masuk jauh ke dalam sistem pernafasan.

Vol. XII No. 24 Th. 1996/1997 


\section{MATERI DAN METODA PENELITIAN}

Materi :

Berupa udara lingkungan kerja serta udara ambien pada industri Ban.

Metoda :

Metoda penelitian gas buang berupa pengambilan titik sampling dengan cara menggunakan metoda transek titik pusat. Parameter yang diuji meliputi : parameter fisika seperti suhu, kelembaban, arah angin, kecepatan angin, kebisingan, dan parameter kimia seperti partikel debu, gas pencemar berupa $\mathrm{SO}_{2}, \mathrm{O}_{x}, \mathrm{NO}_{2}$, $\mathrm{H}_{2} \mathrm{~S}$, dan $\mathrm{NH}_{3}$.

Metoda pengambilan sample gas buang pada penelitian ini dengan cara mengalirkan udara dengan menggunakan Vacum Pump ke dalam tabung Impinger yang didalamnya sudah berisi larutan absorbent yang sudah tertentu untuk tiap gas pencemar yang akan dianalisa. Dengan waktu dan kecepatan yang tertentu, gas buang diserap/diabsorpsi dengan larutan absorbent, lalu larutan absorbent tersebut dianalisa dengan alat Spektrophotometer pada panjang gelombang tertentu sehinggga didapatkan konsentrasi dari masing-masing gas buang. Dengan perhitungan yang tertentu, maka didapatkan kadar/konsentrasi dari masing-masing gas buang tersebut.

a. $\mathrm{SO}_{2}$

Pengukuran gas $\mathrm{SO}_{2}$ dilakukan dengan metoda West Gaeka dimana larutan sample $\mathrm{SO}_{2}$ direaksikan dengan larutan Pararosaniline Hydrochloride 0,04 \%dan larutan Formaldehida $0,2 \%$, selanjutnya dianalisa dengan memakai Spektrophotometer pada panjang gelombang $560 \mathrm{~nm}$.

b. $\mathrm{O}_{\mathrm{x}}$ (Oxidant)

Pengukuran gas oxidant dilakukan dengan cara larutan sample oxidant direaksikan dengan larutan aciditing, selanjutnya dianalisa dengan Spektropho tometer pada panjang gelombang $352 \mathrm{~nm}$.

c. $\mathrm{NH}_{3}$ (Amoniak)

Pengukuran gas $\mathrm{NH}_{3}$ dilakukan dengan cara larutan sample $\mathrm{NH} 3$ direaksikan dengan larutan nessler, selanjutnya dianalisa dengan Spektrophotometer pada panjang gelombang $460 \mathrm{~nm}$.

d. $\mathrm{H}_{2} \mathrm{~S}$ (Hidrogen Sulfida)

Pengukuran gas $\mathrm{H}_{2} \mathrm{~S}$ dilakukan dengan cara larutan sample gas $\mathrm{H}_{2} \mathrm{~S}$ direaksikan dengan larutan Test Amine dan larutan Ferry Chloride dan dianalisa dengan Spektrophotometer pada panjang gelombang $670 \mathrm{~nm}$.

e. $\mathrm{NO}_{2}$ (Nitrogen Oksida)

Pengukuran gas $\mathrm{NO}_{2}$ dilakukan dengan caralarutan sample gas $\mathrm{NO}_{2}$ direaksikan

Majalah Barang Kulit, Karet dan Plastik

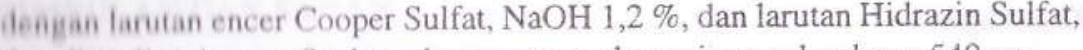
dan dianalisa dengan Spektrophotometer pada panjang gelombang $540 \mathrm{~nm}$.

Carikel Debu

Penuambilan sample dengan metoda High Volume Air Sampling (metoda Handar). Udara dihisap melalui filter fiber glass dengan kecepatan aliran udara 1.11 sampai $1.70 \mathrm{~m}^{3} /$ menit atau 30 - 60 cuft. Partikel tersuspensi dengan diameier $\leqslant 100$ mikron akan dihisap dan tertahan di permukaan filter. Konsentrasi parikel/debu tersuspensi akan didapat dari selisih berat filter setelah sampling dengan berat filter sebelum sampling.

\& Kebisingan

Pengaruh derajad kebisingan dengan metode Sound Level Meter dengan pengukuran range kebisingan $30 \mathrm{dBA}$ sampai dengan $120 \mathrm{dBA}$. Pengukuran dilakukan dengan mengarahkan sensor Sound Level Meter pada sumber kebisingan darijarak yang dekat dan darijarak dimana pekerja berada pada peralatan tersebut, disamping pada ruang kerja juga diukur pada lingkungan pabrik.

\section{HASII. PENELITIAN DAN PEMBAHASAN}

IIASII, PENELITIAN :

\begin{tabular}{|c|c|c|c|c|c|}
\hline \multirow[t]{2}{*}{ No } & \multirow[t]{2}{*}{ Parameter } & \multicolumn{2}{|c|}{ Hasil Analisa } & \multicolumn{2}{|c|}{ Baku Mutu } \\
\hline & & Ambient & Ruang Proses & Ambient ${ }^{1)}$ & Ruang Proses $^{2)}$ \\
\hline I. & o, & $\begin{array}{l}0,4144 * \\
1,6235^{*} \\
0,8840^{*}\end{array}$ & $\begin{array}{l}0,3418^{*} \\
1,4670^{*} \\
0,2580^{*}\end{array}$ & $0,10 \mathrm{ppm}$ & $0,10 \mathrm{ppm}$ \\
\hline 2. & so, & $\begin{array}{l}\mathrm{ttd} \\
\mathrm{ttd} \\
\mathrm{ttd}\end{array}$ & $\begin{array}{l}\mathrm{ttd} \\
\mathrm{ttd} \\
\mathrm{ttd}\end{array}$ & $0,10 \mathrm{ppm}$ & $5,00 \mathrm{ppm}$ \\
\hline 1. & $\mathrm{H}_{3} \mathrm{~S}$ & $\begin{array}{l}0,0216 \\
0,0051 \\
0,0053 \\
\end{array}$ & $\begin{array}{l}0,0253 \\
0,0029 \\
0,0520 \\
\end{array}$ & $0,03 \mathrm{ppm}$ & $10,00 \mathrm{ppm}$ \\
\hline 4 & $\mathrm{NO}_{,}$ & $\begin{array}{c}0,0035 \\
0,0033 \\
\text { ttd }\end{array}$ & $\begin{array}{c}0,0018 \\
t t d \\
0,0095 \\
\end{array}$ & $0,05 \mathrm{ppm}$ & $5,00 \mathrm{ppm}$ \\
\hline 5. & $\mathrm{NH}_{3}$ & $\begin{array}{l}11,7034 * \\
16,5210^{*} \\
18,1179^{*}\end{array}$ & $\begin{array}{c}4,4965 \\
\text { ttd } \\
\text { ttd }\end{array}$ & $2,00 \mathrm{ppm}$ & $18,00 \mathrm{ppm}$ \\
\hline 6. & Debu & $\begin{array}{c}0,2390 \\
1,6880^{*} \\
0,2727 *\end{array}$ & $\begin{array}{l}1,1440 \\
1,2632 \\
1,2430\end{array}$ & $0,26 \mathrm{mg} / \mathrm{m}^{3}$ & $10,00 \mathrm{mg} / \mathrm{m}^{3}$ \\
\hline
\end{tabular}

Vol. XII No. 24 Th. 1996/1997 
Keterangan:

1). Baku mutu berdasarkan Kep. Men 03/MENKLH/II/91

2). Baku mutu berdasarkan NAB (Nilai Ambang Batas) tempat kerja.

*). Hasil Analisa diatas baku mutu yang dipersyaratkan.

\section{PEMBAHASAN}

Parameter Oksidan terukur baik untuk udara ambien serta udara ruang proses produksi, hasilnya sebagai berikut : $0,4144-1,6235$ ppm serta $0,2580-1,4670$ ppm. Baku mutu untuk udara ambien dipersyaratkanm sebesar $0,10 \mathrm{ppm}$, dengan demikian hasil analisa tersebut sudah melebihi baku mutu yang dipersyaratkan. Sedangkan hasil persyaratan bagi ruang proses juga sebesar $0,10 \mathrm{ppm}$, dengan demikian hasil analisa oksidan untuk ruang proses produksi telah diatas ambang batas.

Parameter Sulfur Oksida ( $\mathrm{SO}_{\mathrm{z}}$ ), baik pada ruang proses produksi maupun udara ambien, tidak terdeteksi (Not Detecable).

Parameter Hidrogen Sulfida terukur untuk masing-masing lokasi sampling yaitu berkisar antara $0,0051-0,0216$ ppm untuk udara ambien, sedangkan hasil analisa terukur untuk ruang proses produksi sebesar 0,0029-0,0520 ppm. Persyaratan kadar $\mathrm{H}_{2} \mathrm{~S}$ yang telah ditentukan yaitu sebesar $0,03 \mathrm{ppm}$ untuk udara ambien serta 10,00 ppm untuk ruang kerja. Dengan demikian hasil $\mathrm{H}_{2} \mathrm{~S}$ terukur masih jauh dari ambang batas yang telah dipersyaratkan.

Parameter Nitrogen Oksida $\left(\mathrm{NO}_{\mathrm{x}}\right.$ ) terukur pada ruang proses produksi berkisar antara $0,0018-0,0095 \mathrm{ppm}$, bahkan ada lokasi sampling yang tidak terdeteksi adanya NOx. Sedangkan hasil $\mathrm{NO}_{x}$ terukur pada udara ambien antara $0,003-0,0035 \mathrm{ppm}$. Persyaratan $\mathrm{NO}_{\mathrm{x}}$ bagi ruang proses produksi ditentukan sebesar $5,00 \mathrm{ppm}$ sedangkan untuk udara ambien sebesar 0,05 ppm. Dengan demikian hasil analisa kadar $\mathrm{NO}_{x}$, baik ruang proses produksi maupun udara ambien masih memenuhi baku mutu yang dipersyaratkan.

Parameter debu terukur untuk udara ambien bekisar antara 0,2390 - 1,6880 $\mathrm{mgr} / \mathrm{m}^{3}$ sedang hasil analisa debu terukur untuk ruang proses produksi berkisar antara 1,1440 - 1,2632 mgr $/ \mathrm{m}^{3}$. Baku mutu yang telah dipersyaratkan untuk kadar debu yaitu $0,26 \mathrm{mgr} / \mathrm{m}^{3}$ untuk udara ambien. Dengan demikian hasil analisa debu untuk udara lingkungan ambien sudah diatas standar baku mutu, meskipun ada beberapa lokasi pengambilan sampel debu pada udara ambien yang masih sesuai ketentuan baku mutu yang berlaku.

Parameter Amoniak terukur pada udara ambien berkisar antara 11,7034 $18,1179 \mathrm{ppm}$, hasil tersebut jauh diatas baku mutu sebesar 2,00 ppm. Sedangkan lokasi sampling $\mathrm{NH}_{3}$ pada ruang kerja beberapa diantaranya tidak terdeteksi.

\section{WHIMUILAN DAN SARAN}

\section{GIAIMULILAN}

Ilasil penelitian menunjukkan bahwa tidak terdeteksi adanya Sulfur Dioksida laik di udara umbien maupun udara ruang proses produksi serta Nitrogen Oksida diii Amoniak untuk beberapa titik sampling baik udara ambien maupun ruang proses.

Heberapa hasil analisa telah menunjukkan angka diatas baku mutu yang ielah dipersyaratkan yaitu Oksidan pada udara ambien berkisar antara 0,4144. $1,6215-0,10 \mathrm{ppm}$ baku mutu udara ambien. Sedangkan hasil terukur untuk ruang prosen produksi berkisar antara 0,2580 - 1,4670 ppm $>0,10$ ppm baku mutu ruang inoneil prodiksi

Ifasil analisa parameter Amoniak antara 11,7034- 18,1179 ppm >2,00 ppm hak u mutu udara ambien. Serta debu terukur pada ruang proses produksi mempunyai Liaran $0,2727-1,6880 \mathrm{mgr} / \mathrm{m}^{3}>0,26 \mathrm{mgr} / \mathrm{m}^{3}$.

Ueberapa hasil analisa masih dibawah baku mutu yang telah ditentukan yaitu hasil analisa Hidrogen Sulfida pada udara ambien 0,0051 - 0,0216 ppm $<0,03 \mathrm{ppm}$ hak u mutu udara ambien. Kisaran hasil terukur Hidrogen Sulfida untuk ruang proses aнкаг 0,0029-0,0529 ppm < 10,00 ppm baku mutu udara ruang kerja. Hasil analisa parameter debu terukur pada ruang proses produksi menunjukkan angka 1,140 $1,2612 \mathrm{mgr} / \mathrm{m}^{3}<10,00 \mathrm{mgr} / \mathrm{m}^{3}$.

\section{GANN I}

Perlu penyempurnaan cerobong asap untuk pengeluaran gas buang

Ferlu penyempurnaan Dust Collector dengan efisiensi penangkapan debu optimal

\section{DAFTAR PUSTAKA}

1. Asih. H. Jayadiningrat. Dr. Ir. Dipl. SE, Sumber Pencemaran Udara dan Standar Kualitas Udara, 1994.

2. A.L. Slamet Riyadi. Dr. SKM, Pencemaran Udara, Akademi Teknologi Sanitasi Surabaya, Dep. Kes. RI.

1. Nursamsi Sarengat. Ir, Pengendalian Pencemaran Gas Buang dan Partikel Debu, 1993

4. Perkin. C. Henry, Air Pollution, University Of Arizona

5. Srikandi Fardiaz, Polusi Air dan Udara, Penerbit Kanisius, Yogyakarta, 1992

6. Universitas Gadjah Mada, Kumpulan Makalah Kursus AMDAL A-B, 1989

7. World Resources Institute, Environmental Almanac, Houghton Mifflin Company, Boston, 1993 